\title{
A Novel Method to Achieve Selective Emitter Using Surface Morphology for PERC Silicon Solar Cells
}

\author{
Minkyu Ju ${ }^{1}$, Jeongeun Park ${ }^{1}$, Young Hyun Cho ${ }^{2}$, Youngkuk Kim ${ }^{2}$, Donggun Lim ${ }^{1}$, \\ Eun-Chel Cho ${ }^{2, *}$ iD and Junsin $\mathrm{Yi}^{2, *}$ \\ 1 School of Electronic, Electrical Engineering, Korea National University of Transportation, \\ Chungju 27469, Korea; mkju@ut.ac.kr (M.J.); ac1331@ut.ac.kr (J.P.); dglim@ut.ac.kr (D.L.) \\ 2 School of Information and Communication Engineering, Sungkyunkwan University, Suwon 16419, Korea; \\ yhcho64@skku.edu (Y.H.C.); bri3tain@skku.edu (Y.K.) \\ * $\quad$ Correspondence: echo0211@skku.edu (E.-C.C.); junsin@skku.edu (J.Y.)
}

Received: 24 August 2020; Accepted: 29 September 2020; Published: 6 October 2020

\begin{abstract}
Recently, selective emitter (SE) technology has attracted renewed attention in the Si solar cell industry to achieve an improved conversion efficiency of passivated-emitter rear-contact (PERC) cells. In this study, we presented a novel technique for the SE formation by controlling the surface morphology of Si wafers. SEs were formed simultaneously, that is, in a single step for the doping process on different surface morphologies, nano/micro-surfaces, which were formed during the texturing processes; in the same doping process, the nano- and micro-structured areas showed different sheet resistances. In addition, the difference in sheet resistance between the heavily doped and shallow emitters could be controlled from almost 0 to $60 \Omega$ /sq by changing the doping process conditions, pre-deposition and driving time, and temperature. Regarding cell fabrication, wafers simultaneously doped in the same tube were used. The sheet resistance of the homogeneously doped-on standard micro-pyramid surface was approximately $82 \Omega / s q$, and those of the selectively formed nano/micro-surfaces doped on were on 62 and $82 \Omega /$ sq, respectively. As a result, regarding doped-on selectively formed nano/micro-surfaces, SE cells showed a JSC increase $\left(0.44 \mathrm{~mA} / \mathrm{cm}^{2}\right)$ and a fill factor (FF) increase $(0.6 \%)$ with respect to the homogeneously doped cells on the micro-pyramid surface, resulting in about $0.27 \%$ enhanced conversion efficiency.
\end{abstract}

Keywords: selective emitter; surface morphology; doping process; PERC; solar cell

\section{Introduction}

Presently, crystalline silicon (c-Si) solar cells are the leading product in the solar cell market, owing to their efficiency and low production cost [1,2], and this trend is expected to continue [3]. In terms of cell fabrication technology, passivated-emitter rear-contact (PERC) cells have become the mainstream product in the mass production of c-Si solar cells, owing to their high efficiency and cost-effectiveness [4-6]. According to an ITRPV (International Technology Roadmap for Photovoltaics) report, the market share of PERC technology in 2019 was over 30\% and, according to estimates, it will exceed $60 \%$ by 2030 [3]. With continuous development over the past few years, PERC cell technology has already achieved a mass-production efficiency exceeding 21\% [6]. Therefore, to further improve the efficiency, most solar cell companies are trying to develop new technologies and apply them to their production lines. The selective emitter (SE) technology has recently again attracted renewed attention, owing to its high efficiency [3-10].

SE technology has the following advantages. First, it has low sheet resistance because the high doping concentration under the electrodes lowers the contact resistance, leading to an improvement in the fill factor (FF). Second, better surface passivation on the high-sheet-resistance area enhances the 
short-circuit current density $\left(\mathrm{J}_{\mathrm{SC}}\right)$ and open-circuit voltage $\left(\mathrm{V}_{\mathrm{OC}}\right)$ [6-10]. There are several methods to create an SE, such as dopant-paste printing [11,12], inkjet printing [13,14], etch-back [15,16], and laser techniques [17-24]. However, most of these techniques are applied immediately before or after the doping process, so there are risks to the solar cell manufacturing process. As shown in Figure 1, SE technologies such as dopant-paste printing and inkjet printing are susceptible to contamination; in other words, there is a risk of contaminants spreading into the silicon during the high-temperature doping process [11-14]. Etch-back and etch-paste techniques result in the loss of reflectivity due to smoothing of the texture surfaces [15-17]. The laser doping method can damage the silicon surface, which is detrimental to the open-circuit voltage $\left(\mathrm{V}_{\mathrm{OC}}\right)[18,19]$. In addition, most $\mathrm{SE}$ technologies are likely to cause misalignment, which results in over-alignment losses in the alignment with the front electrode during the printing process [8-23]. Recently, as a new technology to overcome this, the development of a new SE to mitigate the recombination loss by the heavily doped epitaxial layer selectively grown after the passivation process, has been reported [24].

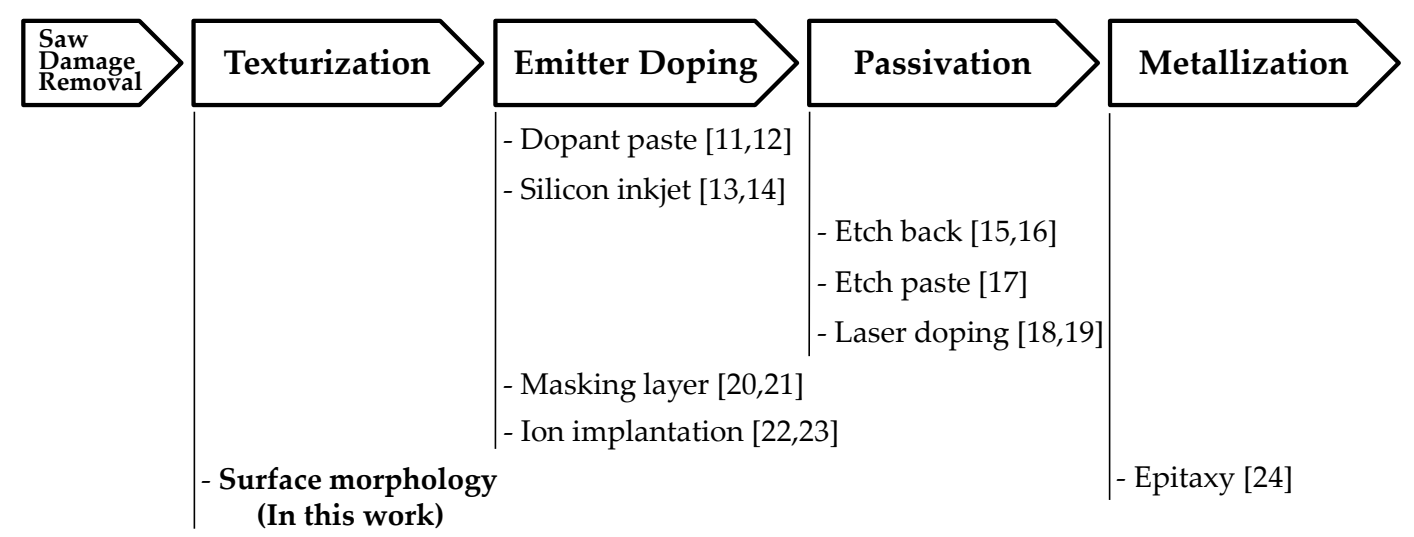

Figure 1. Comparison between the processes for selective emitter (SE) technologies used in our study and in previous studies [11-24].

In this study, a novel SE technique that uses selective nanosurface morphologies for a heavy emitter area was proposed before the pyramid texturing process [3-24]. A new SE technique that uses each different surface morphology was proposed. Even though the nano/micro-structured areas were doped in a single doping process, they exhibited different sheet resistances. In addition, the differences in sheet resistance could be controlled during the doping process by altering the temperature, pre-deposition time, and drive-in time. Importantly, using this SE technique could perform a sufficient cleaning process before the doping process, so there was less contamination risk to the solar cell manufacturing process. Furthermore, the loss from the mismatch between the heavily doped region and the front electrodes by screen-printing could be drastically reduced. Therefore, compared to conventional SE, there was less risk such as surface damage, return loss, and over-alignment loss.

\section{Experimental Details}

In this experiment, p-type boron-doped 6-inch single c-Si wafers with a resistivity of $1-1.5 \mathrm{ohm}$-cm and a thickness of $180 \pm 20 \mu \mathrm{m}$ were used. Initially, the c-Si wafers were immersed for $10 \mathrm{~min}$ at approximately $75^{\circ} \mathrm{C}$, in a mixed etching solution with a concentration of $5 \mathrm{wt} \%$ sodium hydroxide $(\mathrm{NaOH})$ and $0.75 \mathrm{wt} \%$ sodium hypochlorite $(\mathrm{NaOCl})$, to ensure saw damage removal (SDR). The wafers were rinsed in flowing DI water, followed by hydrochloric acid $(\mathrm{HCl})$ and hydrofluoric acid $(\mathrm{HF})$, to remove the metal ions and native oxides on the surface. Finally, the wafers were rinsed again in the flowing DI water and then dried. 


\subsection{Characteristics of Phosphorus Doping According to Nanosurface Morphology}

To obtain the nanostructure on one side, two cleaned SDR wafers in contact with each other were placed on the etching carrier. The nanostructure texture was obtained through vapor-texturing using an etching solution of $\mathrm{HF}: \mathrm{HNO}_{3}=7: 3$ volume ratio to form a uniform nanostructure on the surface [25]. The morphologies of the samples were controlled, and the shape and size of the surface nanostructure were modified during etching by varying the post-etching time between 0 and $3 \mathrm{~min}$ in an $\mathrm{HF}: \mathrm{HNO}_{3}: \mathrm{CH}_{3} \mathrm{COOH}$ isotropic etching solution with a volume ratio of (1:100:50), at room temperature. After vapor texturing, the samples were immersed for $10 \mathrm{~min}$ at $75^{\circ} \mathrm{C}$ in the standard clean 1 (SC1) solution of $\mathrm{NH}_{4} \mathrm{OH}: \mathrm{H}_{2} \mathrm{O}_{2}: \mathrm{H}_{2} \mathrm{O}$ (1:1:5 volume ratio) to remove the chemicals remaining on the surface. Then, the samples were rinsed in flowing DI water followed by HF, to remove the native oxides on the surface. Finally, the wafers were rinsed again in flowing DI water and were dried. To form the micro-pyramid structure on the other surface of the samples, a 160-nm thickness silicon nitride $\left(\mathrm{SiN}_{\mathrm{X}}\right)$ texturing barrier was deposited on the nanosurface using plasma-enhanced chemical vapor deposition (PECVD). Then, the remaining silicon particles on the surface were removed from the samples through SC1 cleaning. The samples were immersed for $30 \mathrm{~min}$ at $81-83^{\circ} \mathrm{C}$ in a mixed solution of $2 \mathrm{wt} \%$ sodium hydroxide $(\mathrm{NaOH}), 6.25 \mathrm{wt} \%$ sodium silicate $\left(\mathrm{Na}_{2} \mathrm{SiO}_{3}\right)$, and $12.5 \mathrm{vol} \%$ isopropyl alcohol (IPA) for micro-pyramid texturization [26]. For removal of the $\mathrm{SiN}_{X}$ texture-barrier film formed on the nanostructure, the samples were immersed for $10 \mathrm{~min}$ at room temperature in buffered HF (BHF, $\mathrm{NH}_{4} \mathrm{~F}: \mathrm{HF}=6: 1$ ). The samples were rinsed in flowing DI water, followed by $\mathrm{HCl}$ and $\mathrm{HF}$, to remove the metal ions and native oxides on the surface. Finally, the wafers were rinsed again in flowing DI water and dried.

Phosphorus doping was performed at a temperature of $825^{\circ} \mathrm{C}$ for $10 \mathrm{~min}$ in a quartz-tube furnace using $\mathrm{POCl}_{3}$ for the formation of an emitter layer on the surface of the samples, with each sample having a different surface. To remove the phosphorus silicate glass (PSG) layer deposited on the surface, the sample was immersed in an HF solution for $30 \mathrm{~s}$, and then washed with DI water and dried. The sheet resistances of the emitters formed according to the varied surface structure were measured at similar positions, at a uniform distance apart, through a four-point probe. The surface morphology of samples with varied nanostructure was observed using scanning electron microscope (SEM) images.

\subsection{Characteristics of Nanosurface Emitter Layer According to Doping Condition}

To observe the variation in sheet resistance according to the phosphorus doping condition in the variable surface morphology, wafers formed on both sides with a nanostructure and a micro-pyramid structure were used. The prepared samples were cleaned with $\mathrm{HCl}$ and $\mathrm{HF}$, rinsed with flowing DI water, and dried. The cleaned samples were processed in a quartz-tube furnace using $\mathrm{POCl}_{3}$ at a temperature range of $805-860{ }^{\circ} \mathrm{C}$ for $10 \mathrm{~min}$, to ensure a varied sheet resistance for the shallow emitter on the surface. Subsequently, the samples were processed in a quartz-tube furnace using $\mathrm{POCl}_{3}$ for 10-30 min at $860^{\circ} \mathrm{C}$, to ensure a varied sheet resistance for the deep emitter on the surface. After removing the PSG layer by using HF, the sheet resistances of the emitter formed on the nano- and micro-pyramid structures were measured and analyzed. The analysis of the number of phosphorus atoms in the emitter with varied surface morphology was performed using a CAMECA IMS $7 f$ magnetic-sector secondary ion mass spectroscope (SIMS) (CAMECA in Gennevilliers, France).

\subsection{Fabrication of Novel SE Solar Cells Using Surface Morphology}

To analyze the characteristics of the solar cells according to their surface morphology, they were designed to have a nanostructure (nano), micro-pyramid structure (pyramid), and nano-micro-SE structure (selective). Initially, all the fabricated samples had a uniform nanostructure on the front side from the cleaned SDR by vapor-texturing [25]. For the sample with the nano-micro-SE structure, a $\mathrm{SiN}_{X}$ texturing barrier was deposited on the front side using PECVD. The front texture barrier was patterned using the acid etching resistance through screen-printing using a front-grid mask with a line 
width of about $100 \mu \mathrm{m}$, and spacing of $1.312 \mathrm{~mm}$. Then, the sample was immersed for $10 \mathrm{~min}$ at room temperature, and BHF was used to pattern the surface by removing the $\mathrm{SiN}_{X}$ texture barrier. All the samples were immersed for $10 \mathrm{~min}$ at $75^{\circ} \mathrm{C}$ in an SC1 solution to remove the remaining chemicals on the surface. Then, the acid etching resistance on the surface was removed through SC1 cleaning. The two types of samples were immersed for $30 \mathrm{~min}$ at $81-83^{\circ} \mathrm{C}$ in a solution of $2 \mathrm{wt} \% \mathrm{NaOH}, 6.25$ $w \mathrm{t} \% \mathrm{Na}_{2} \mathrm{SiO}_{3}$, and $12.5 \mathrm{vol} \%$ IPA for micro-pyramid texturization [26]. Two types of samples were patterned with the nano-micro-SE structure and micro-pyramid structure. To remove the $\mathrm{SiN}_{X}$ texture barrier film of the patterned nano-micro-SE structure of the samples, these were immersed in BHF for $10 \mathrm{~min}$ at room temperature. All the samples were rinsed in flowing DI water, followed by $\mathrm{HCl}$ and $\mathrm{HF}$, to remove the metal ions and native oxides on the surface. Finally, the wafers were rinsed again in flowing DI water and dried. The surface morphology of the patterned nano- and micro-pyramid structures was observed using SEM. The emitter layer was formed in a quartz tube using $\mathrm{POCl}_{3}$ at 830 ${ }^{\circ} \mathrm{C}$ for $10 \mathrm{~min}$. The PSG layer was removed and etched on the rear side using the InOxide facility of RENA Technologies GmbH.

For the formation of standardized PERC structures, the front side was passivated using PECVD-SiN ${ }_{X}$ (single layer with refractive index 2.05), and the rear side was passivated with a stacked layer of atomic layer deposition aluminum oxide (ALD- $\left.\mathrm{Al}_{2} \mathrm{O}_{3}\right)$ and PECVD-SiNX. Line-shaped laser contact openings (LCO) were formed on the rear side using a picosecond laser. The Ag front grid metal was printed with an aligned nano-micro-SE patterned with $\mathrm{Ag}$ paste. The grid pattern design of the front electrode had $40-\mu \mathrm{m}$ finger width and 1.312-mm spacing. The rear side was screen-printed on the whole area with a commercially available $\mathrm{Al}$ paste, and a furnace firing step completed the PERC cell process. To confirm the Ag printing characteristics of the front electrode formed by each surface structure, the shape of the electrode was observed using an optical microscope (OM), and the line width was measured. The current density-voltage $(\mathrm{J}-\mathrm{V})$ measurement of the solar cell fabricated by each surface structure was analyzed under the standard condition of AM $1.5 \mathrm{G}\left(100 \mathrm{~mW} / \mathrm{cm}^{2}\right)$ at 25 ${ }^{\circ} \mathrm{C}$. The internal quantum efficiency was measured in the wavelength range of 300 to $1100 \mathrm{~nm}$ using the QEX7 IPCE(Incident-Photon-to-electron Conversion Efficiency) system (PV Measurements, Inc. in Washington, WA, USA).

\section{Results}

\subsection{Characteristics of Phosphorus Doping According to Nanosurface Morphology}

A nanostructured surface with an approximate size of $50 \mathrm{~nm}$ was formed through chemical vapor texturing of the cleaned SDR wafers, as shown in Figure 2a,e. Further post-etching of the nanostructured surface for immersion durations of 1,2 , and 3 min changed the sizes of the nanostructures to approximately 100, 200, and $300 \mathrm{~nm}$, respectively. The SEM images in Figure 2a-d show the changed size of the nanostructures formed after vapor-texturing with post-etching. Figure $2 \mathrm{e}, \mathrm{f}$ shows the cross-section of nano-vapor texturing and micro-pyramid texturing.

In Figure 3, it can be observed that the average emitter sheet resistance for the micro-pyramid structure surface was $98.5 \Omega / \mathrm{sq}$. At this time, for the 50-nm nanostructure surface (shown in Figure 2a,e), the emitter sheet resistance was $61.1 \Omega / \mathrm{sq}$. By changing the nanostructure size to approximately 100 , 200 , and $300 \mathrm{~nm}$, the emitter sheet resistance was observed to increase to $82.0,86.4$, and $88.8 \Omega / \mathrm{sq}$. As can be observed in Figure 3, owing to the different factors, the sheet resistance for the micro-pyramid structure was 0.64 (nano-vapor texture) for the 50-nm size, 0.81 (post-etching: $1 \mathrm{~min}$ ) for the 100-nm size, 0.85 (post-etching: $2 \mathrm{~min}$ ) for the 200-nm size, and 0.88 (post-etching: $3 \mathrm{~min}$ ) for the $300-\mathrm{nm}$ size. The difference factor index was gradually increased to 1 , which was the reference value for the micro-pyramid structure as the increased size of the nanostructure. As a result, the difference factor index for the novel nano-micro-SE structure, being lower than 1, was better. 


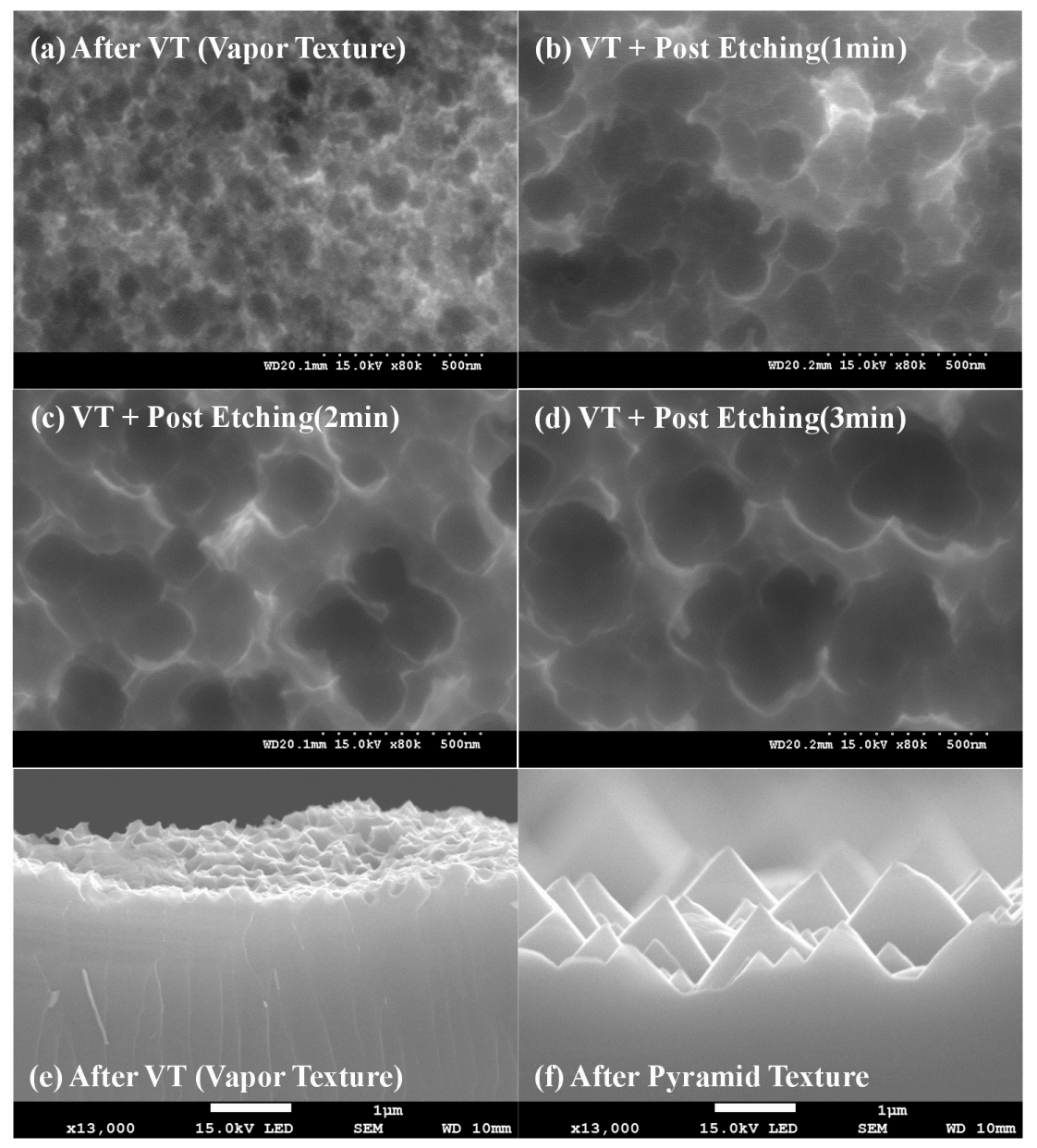

Figure 2. Changes in surface morphology according to nanostructure of vapor texture (a) and after post-etching for 1 (b), 2 (c), and $3 \mathrm{~min}(\mathbf{d})$; cross-section of nanostructure from the vapored-texture process (e); cross-section of micro-pyramid structure from the pyramid textured process (f).

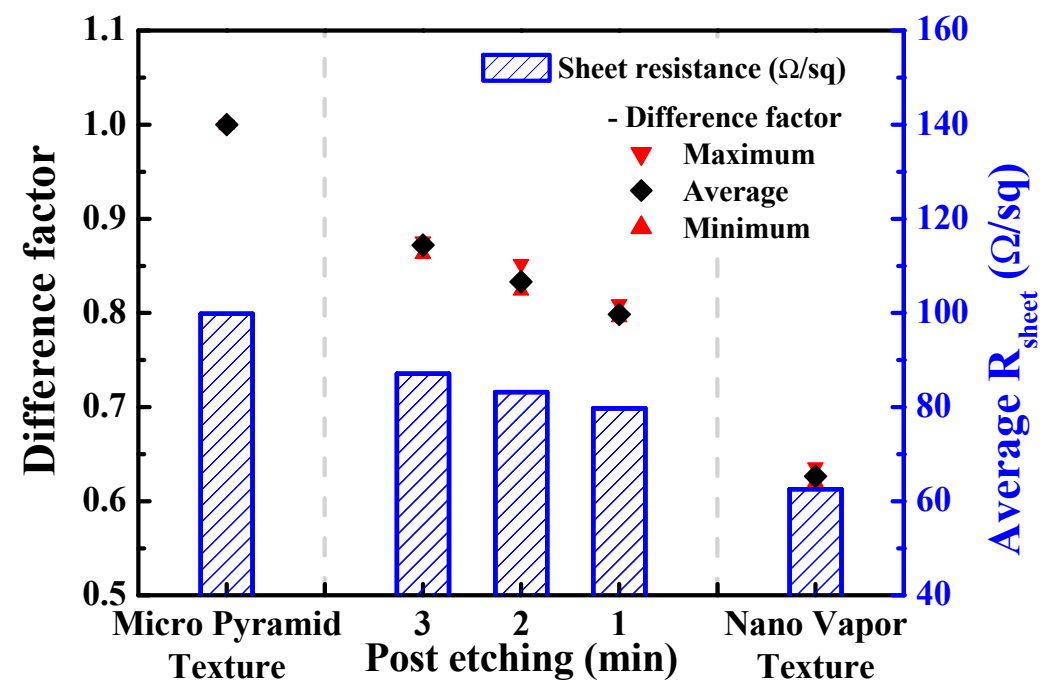

Figure 3. Change in emitter sheet resistance after phosphorus doping process, according to the variation in surface morphology. 


\subsection{Characteristics of Phosphorus Doping According to Nanosurface Morphology}

The samples, with approximately 50-nm size nanostructure on one side and micro-pyramid on the other side, were analyzed with the difference factor index of surface morphology through a doping process about the variation of temperature and time from a high sheet resistance to low sheet resistance. Figure 4 showed the results of the difference factor index of surface morphology by the variation in sheet resistance. For the deep emitter doping conditions, during $30 \mathrm{~min}$ at $860{ }^{\circ} \mathrm{C}$, the average sheet resistances obtained for the pyramid-structured and nanostructured surfaces were 40 and $39 \Omega / \mathrm{sq}$, respectively. In this time, the difference factor index for the $50 \mathrm{~nm}$ nanostructured- and micro-pyramid-structured surfaces was 0.97 , which was attributed to almost equal sheet resistance characteristics for both surfaces. Figure 4 shows the results, and it is observed that as the sheet resistance increased by the doping process condition from a low sheet resistance, the difference factor index became smaller and the SE characteristic was increased. The best difference factor index region of the SE characteristic was when the doping condition with the sheet resistance for the pyramid structure surface was approximately 100 to $150 \Omega / \mathrm{sq}$, and for the nanostructured surface, the range was about 74 to $122 \Omega$ /sq with the difference factor converged to the level of 0.76 . This result was compared with the difference factor index of 0.64 shown in Figure 3. The nano-vapor texture was predicted to result from some large-sized nanostructure. Further, sheet resistance of more than $150 \Omega /$ sq on the pyramid-structured surface was obtained by the doping process condition, and the difference factor index increased for a sheet resistance up to $360 \Omega$ /sq. The experimental results have shown a sheet resistance of approximately $360 \Omega /$ sq for the shallow emitter, and limited change occurred in the sheet resistance according to the surface morphology, whereas the deep emitter had a sheet resistance of 40 $\Omega /$ sq.

The variation in sheet resistance for the doping condition between the nanostructures and the micro-pyramid structure (as shown in Figure 3) indicated a reduced to maximum sheet resistance in the range of about 100 to $150 \Omega$ sq by the size of the nanostructure. It can be seen that the SE characteristic was maximized in this doping region. Shown in Figure 4, the sheet resistance of the "A" sample as the shallow emitter and the " $\mathrm{B}$ " sample as the general emitter were analyzed by SIMS to investigate the factors of change in sheet resistance of the nano- and micro-surface structure according to the doping condition.

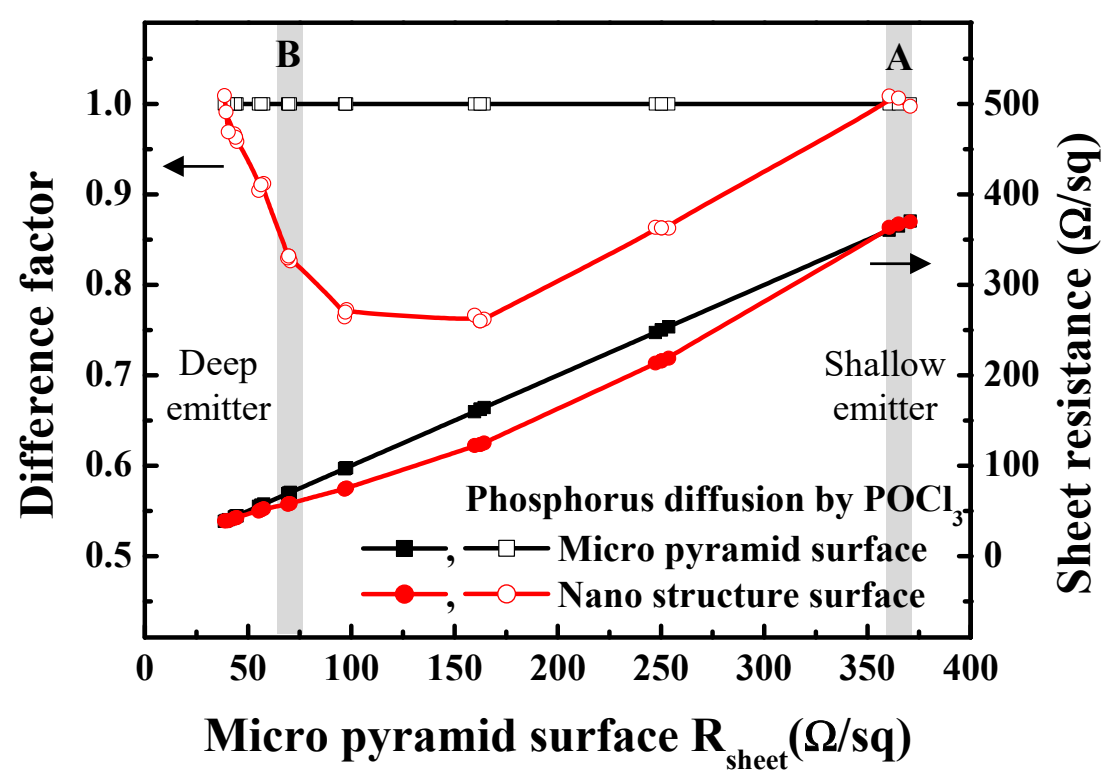

Figure 4. Change in emitter sheet resistance of micro-pyramid structure and nanostructure, according to the doping process condition. 
The SIMS result in Figure 5 indicated that the analysis of the surface morphology of the sample can be measured by the change in silicon $(\mathrm{Si})$ intensity and phosphorus $(\mathrm{P})$ concentration according to the sputter time. On the surface of the nanostructures shown in Figure $5 \mathrm{a}, \mathrm{c}$, the signal of the initial $\mathrm{Si}$ was low, and it was detected as $3 \times 10^{3} \mathrm{cps}$ level. After that, it increased rapidly and then stabilized at $6 \times 10^{3} \mathrm{cps}$ level over $300 \mathrm{~s}$, and an intensity of $7 \times 10^{3} \mathrm{cps}$ level was detected over $550 \mathrm{~s}$. On the surface of the micro-pyramid structure shown in Figure $5 b, d$, the low signal of the initial Si was higher, and it was detected at the level of $6 \times 10^{3}$ and $4 \times 10^{3} \mathrm{cps}$ compared with the nanosurface. It can be observed that it is relatively easier to detect $S i$ than the nanostructure surface. In other words, the doped silicon surface of the nanostructure morphology was coated with many dopant materials, more than the micro-pyramid surface.
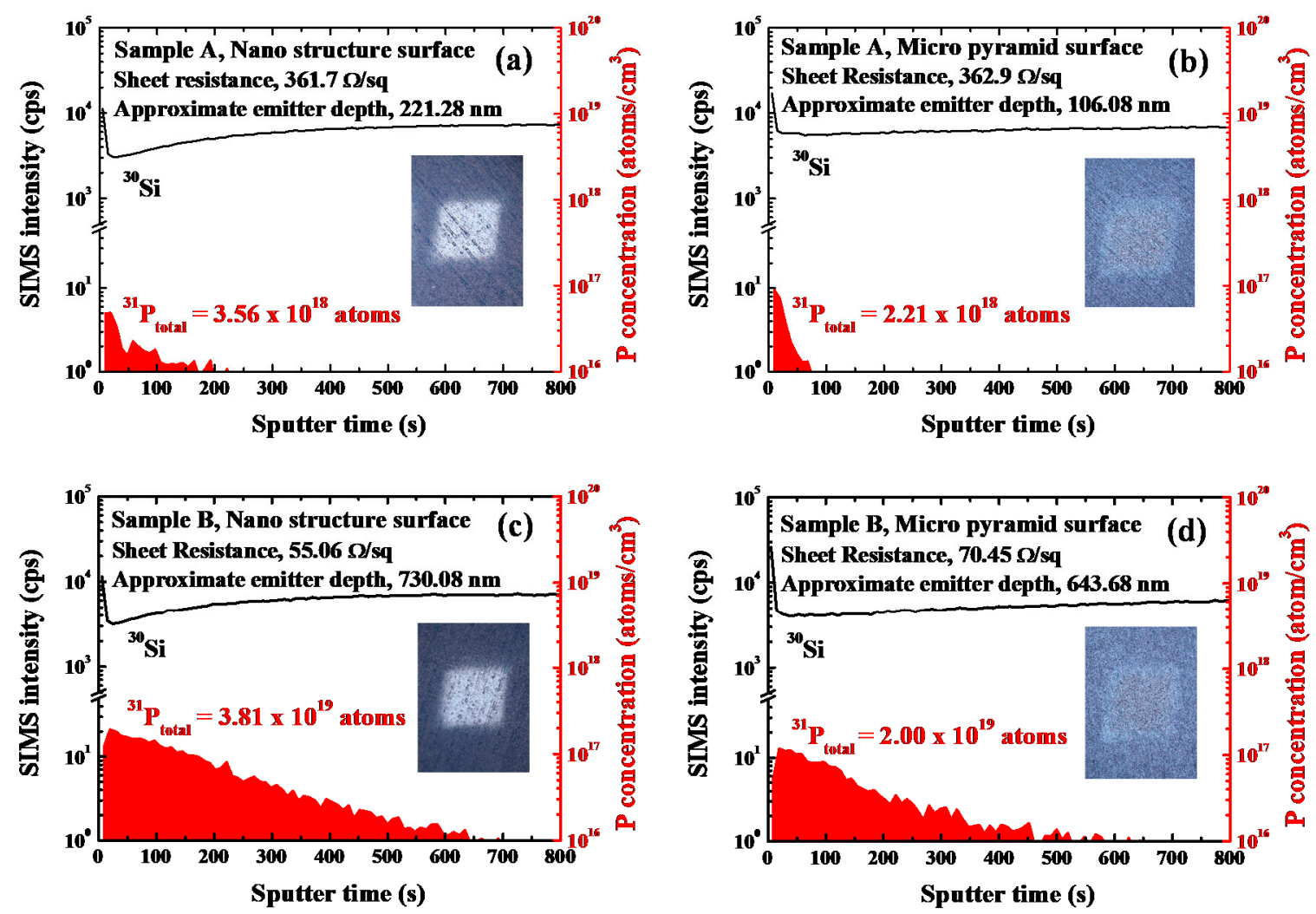

Figure 5. Secondary ion mass spectroscope (SIMS) analysis of surface morphology according to the doping process condition, (a) nanostructure surface in shallow-doping condition A, (b) micro-pyramid structure surface in shallow-doping condition A, (c) nanostructure surface in traditional-doping condition B, (d) micro-pyramid structure surface in traditional-doping condition B.

The results of the analysis of the P concentration by depth to SIMS analysis did not show accurate values due to the shape of the surface structure [27]. However, the results of that detected by SIMS are valid in the comparative analysis of the total amount of $\mathrm{P}$ in the pyramid structure and the nanostructure. In Figure 5a, for the "A" sample of nanostructure morphology, the total amount of $P$ detection concentration is $3.56 \times 10^{18}$ atoms $/ \mathrm{cm}^{3}$ at a sheet resistance of $361.7 \Omega / \mathrm{sq}$. Regarding the micro-pyramid morphology of the " $\mathrm{A}$ " sample, the total amount of $\mathrm{P}$ detection concentration was $2.21 \times 10^{18}$ atoms $/ \mathrm{cm}^{3}$ and the sheet resistance was $362.9 \Omega / \mathrm{sq}$, as shown in Figure $5 \mathrm{~b}$. In the similar sheet resistance, approximately $360 \Omega /$ sq by shallow doping was the highest total amount of detected concentration of $\mathrm{P}$ for the nanostructure morphology compared with the micro-pyramid structure. This result is due to the fact that many dopant materials were inactive on the large surface area of the nanostructure surface by the shallow doping process [28]. 
In Figure $5 c$, for the " $B$ " sample with the SE characteristic of nanostructure morphology, the total amount of $\mathrm{P}$ detection concentration was $3.81 \times 10^{19}$ atoms $/ \mathrm{cm}^{3}$ at a sheet resistance of 55.06 $\Omega / s q$. For the micro-pyramid surface morphology of "B" samples, the total amount of $\mathrm{P}$ detection concentration was $2.00 \times 10^{19}$ atoms $/ \mathrm{cm}^{3}$ and sheet resistance $70.45 \Omega / \mathrm{sq}$, as shown in Figure $5 \mathrm{~d}$. Even under the doping conditions of " $\mathrm{B}$ " samples with the SE characteristic, the total amount of $\mathrm{P}$ doped with the surface characteristics of the nanostructure was higher than that of the pyramid structure. In deep doping conditions, the emitter layer became deeper, and the emitter from the deeper part of the nanostructure was fused $[29,30]$. As a result, for the deeper emitter doping conditions, it had a similar sheet resistance of approximately $40 \Omega / \mathrm{sq}$ and a difference factor index of approximately 1 for the nanostructured surface and the micro-textured surface, as shown in Figure 4.

\subsection{Mechanism of SE Formation by Nano-Micro-Morphology}

The results of sheet resistance analysis in Figures 3 and 4 clearly shows that the best SE structure had a smaller size of the nanostructure, and the doping process condition for the sheet resistance region on the pyramid structure was $100-150 \Omega /$ sq.

Figure 6 shows the SE mechanism in which nanostructures and micro-pyramid structures were formed through the doping process. The local nanostructures for SEs were formed at the texture processing stage with pyramidal structures. The formed textured surface structure had two surface structures simultaneously, as shown in Figure 6a. To produce emitter layer formation, the phosphorus silicate glass (PSG) layer was formed on the surface of the silicon by a pre-deposition process of $\mathrm{POCl}_{3}$ doping in a quartz tube furnace, as shown in Figure $6 \mathrm{~b}$. The report of Catherine et al. analyzes in detail the thickness of the formed PSG layer and the depth of the emitter formed in the peaks, valleys, and flank of the pyramid structure during the doping process [31]. It can be seen from the literature that the PSG layer in the valley position " $\mathrm{A}$ " is formed relatively thick in the pyramid structure compared to the peak and flank as shown in Figure $6 \mathrm{~b}$. In the nanostructure, it can be understood that the thick PSG layer formed more than the pyramid structure thick PSG layer because the valley position " $A$ " had more frequency than the pyramid structure with respect to the same area. As a result, the doped silicon surface of the nanostructure morphology was coated with many dopant materials more than the surface of the micro-pyramid. Dastgheib-Shirazi et al. reported an analysis of the depth variation of the thermally diffused emitter according to the thickness of the PSG layer formed in the doping process [32]. It can be seen from the literature that the thick PSG layer formed a higher surface concentration of phosphorus, forming a deeper emitter layer through the thermal diffusion of the doping process, as shown in Figure 6c. Moreover, it can be seen from the literature that deeper emitters for the micro-pyramid structure were formed in the peak " $\mathrm{D}$ " than in the valleys " $\mathrm{B}$ " and flanks " $\mathrm{C}$ " [31]. In the nanostructure region, it can be understood that the sheet resistance was lower than that in the micro-pyramid structure formed by a higher frequency structure valley " $\mathrm{A}$ " of a thicker PSG layer and the deep diffused layer of peak " $\mathrm{D}$ " through the emitter doping process. In conclusion, the surface morphology of nanostructure and micro-pyramid structure was through the conventional thermal diffusion emitter doping process becoming the novel SE structure as shown in Figure 7. 
Nano structure [25] Micro pyramid structure [26]

(a) Texturing process

\section{Selective structure formation}

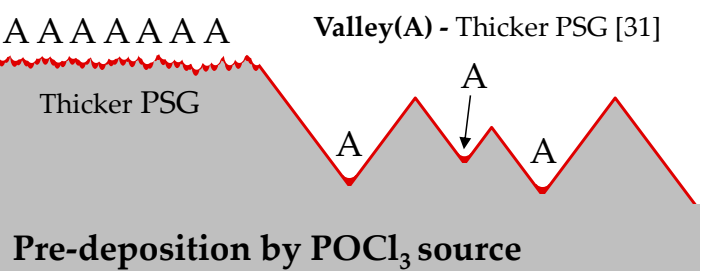

(c) Emitter doping process, step II

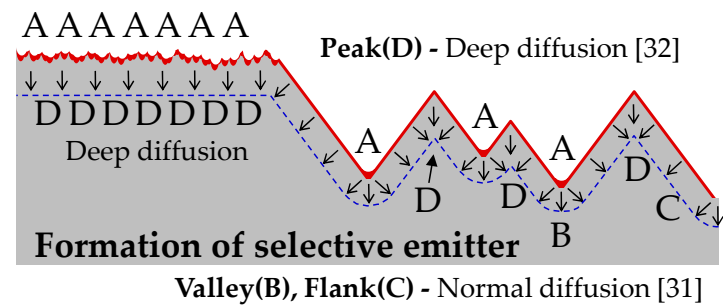

Figure 6. Formation mechanism of the novel selective emitter (SE) according to surface morphology, (a) selective structure formation on texturing process [25,26], (b) phosphorus pre-deposition on doping process [31], (c) phosphorus diffusion on doping process [31,32].
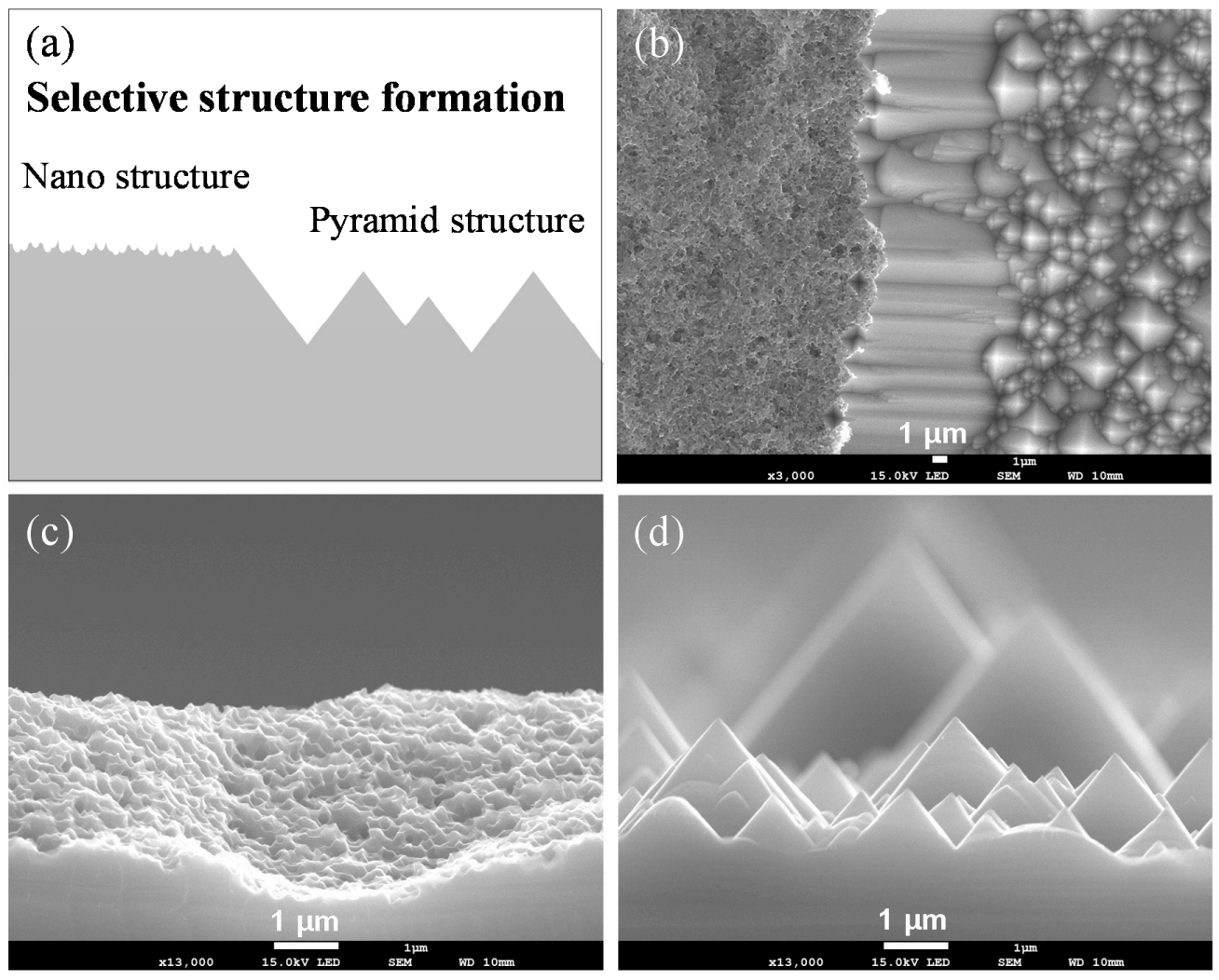

Figure 7. SEM image of the novel SE surface using a nanostructure and a micro-pyramid structure, (a) schematic diagram of the novel SE structure, (b) top view of the novel SE surface in $3 \mathrm{~K}$ magnification, 
(c) cross-section view of the nanostructure side in $13 \mathrm{~K}$ magnification, (d) cross-section view of the micro-pyramid structure side in $13 \mathrm{~K}$ magnification. Included in all is scale bar of $1 \mu \mathrm{m}$.

\subsection{Fabrication of Novel SE Solar Cell.}

Figure 7 shows the schematic diagram Figure 7a of the SE using a nano-micro-pyramid structure and the SEM analysis of the fabricated samples. Figure $7 \mathrm{~b}$ shows the surface of the novel SE structure sample analyzed through SEM at $3 \mathrm{~K}$ magnification on which the nanostructure and micro-pyramid structure were formed together. Figure $7 \mathrm{c}$,d show the enlarged SEM result of the cross-section of the nanostructure and micro-pyramid structure at $13 \mathrm{~K}$ magnification. In the nanostructure of Figure $7 \mathrm{c}$, as described in the mechanism of SE formation by the surface morphology of Figure 6, the valley and the peak observed had a higher frequency compared with the micro-pyramid structure in Figure $7 \mathrm{~d}$.

Table 1 and Figure 8 show the best $\mathrm{J}-\mathrm{V}$ characteristics of the solar cells fabricated with nanostructure cells (NSC), micro-pyramid structure cells (MPC), and the novel SE structure cells (SEC), respectively. The J-V curve results from the NSC emitter had a sheet resistance of $62 \Omega / \mathrm{sq}$, short-circuit current density (JSC) of $39.81 \mathrm{~mA} / \mathrm{cm}^{2}$, open-circuit voltage $\left(\mathrm{V}_{\mathrm{OC}}\right)$ of $638 \mathrm{mV}$, fill factor $(\mathrm{FF})$ of $79.82 \%$, and conversion efficiency of $20.27 \%$. The J-V curve results from the MPC emitter had sheet resistance of 82 $\Omega / \mathrm{sq}$, short-circuit current density $\left(\mathrm{J}_{\mathrm{SC}}\right)$ of $40.35 \mathrm{~mA} / \mathrm{cm}^{2}$, open-circuit voltage $\left(\mathrm{V}_{\mathrm{OC}}\right.$ ) of $647 \mathrm{mV}$, fill factor (FF) of $79.00 \%$, and conversion efficiency of $20.61 \%$. The NSC showed a short-circuit current density (JSC) of $0.54 \mathrm{~mA} / \mathrm{cm}^{2}$ and an open-circuit voltage $\left(\mathrm{V}_{\mathrm{OC}}\right)$ of $9 \mathrm{mV}$, which was degraded compared to that of the MPC. As shown in this result, it was difficult to emitter passivate the nanostructure surface compared to the micro-pyramid surface [29]. However, the NSC showed $0.82 \%$ improvement in the fill factor (FF) compared to the MPC. The improved fill factor (FF) in the NSC can be seen in the literature as an improved series resistance by electrode contact with the sheet resistance of the front emitter [33]. Despite improvements in the fill factor (FF) of the NSC, the degradation of efficiency characteristics due to short circuit current density $\left(\mathrm{J}_{S C}\right)$ and open-circuit voltage $\left(\mathrm{V}_{\mathrm{OC}}\right)$ was due to the low sheet resistance characteristics and higher recombination characteristics [29].

Table 1. Best and average solar cell characteristics according to surface structure with a comparison of sheet resistance.

\begin{tabular}{|c|c|c|c|c|c|c|}
\hline \multirow{2}{*}{$\begin{array}{c}\text { Light J-V Analysis } \\
\text { Sheet Resistance of Emitter } \\
(\Omega / \mathrm{sq})\end{array}$} & \multicolumn{2}{|c|}{$\begin{array}{l}\text { Nanostructure } \\
\text { Cell (NSC) }\end{array}$} & \multicolumn{2}{|c|}{$\begin{array}{l}\text { Micro-Pyramid } \\
\text { Cell (MPC) }\end{array}$} & \multicolumn{2}{|c|}{$\begin{array}{l}\text { SE Cell (SEC) } \\
\text { Low/High }\end{array}$} \\
\hline & \multicolumn{2}{|c|}{62} & \multicolumn{2}{|c|}{82} & \multicolumn{2}{|c|}{$62 / 82$} \\
\hline $\begin{array}{c}\text { Cell remark } \\
\text { (9 samples fabricated) }\end{array}$ & Best & Average & Best & Average & Best & Average \\
\hline $\mathrm{J}_{\mathrm{SC}}\left(\mathrm{mA} / \mathrm{cm}^{2}\right)$ & 39.81 & 39.07 & 40.35 & 40.24 & 40.79 & 40.63 \\
\hline $\mathrm{V}_{\mathrm{OC}}(\mathrm{V})$ & 0.638 & 0.637 & 0.647 & 0.643 & 0.643 & 0.642 \\
\hline Fill Factor (\%) & 79.82 & 80.18 & 79.00 & 78.61 & 79.60 & 79.29 \\
\hline Efficiency (\%) & 20.27 & 19.94 & 20.61 & 20.35 & 20.88 & 20.67 \\
\hline
\end{tabular}



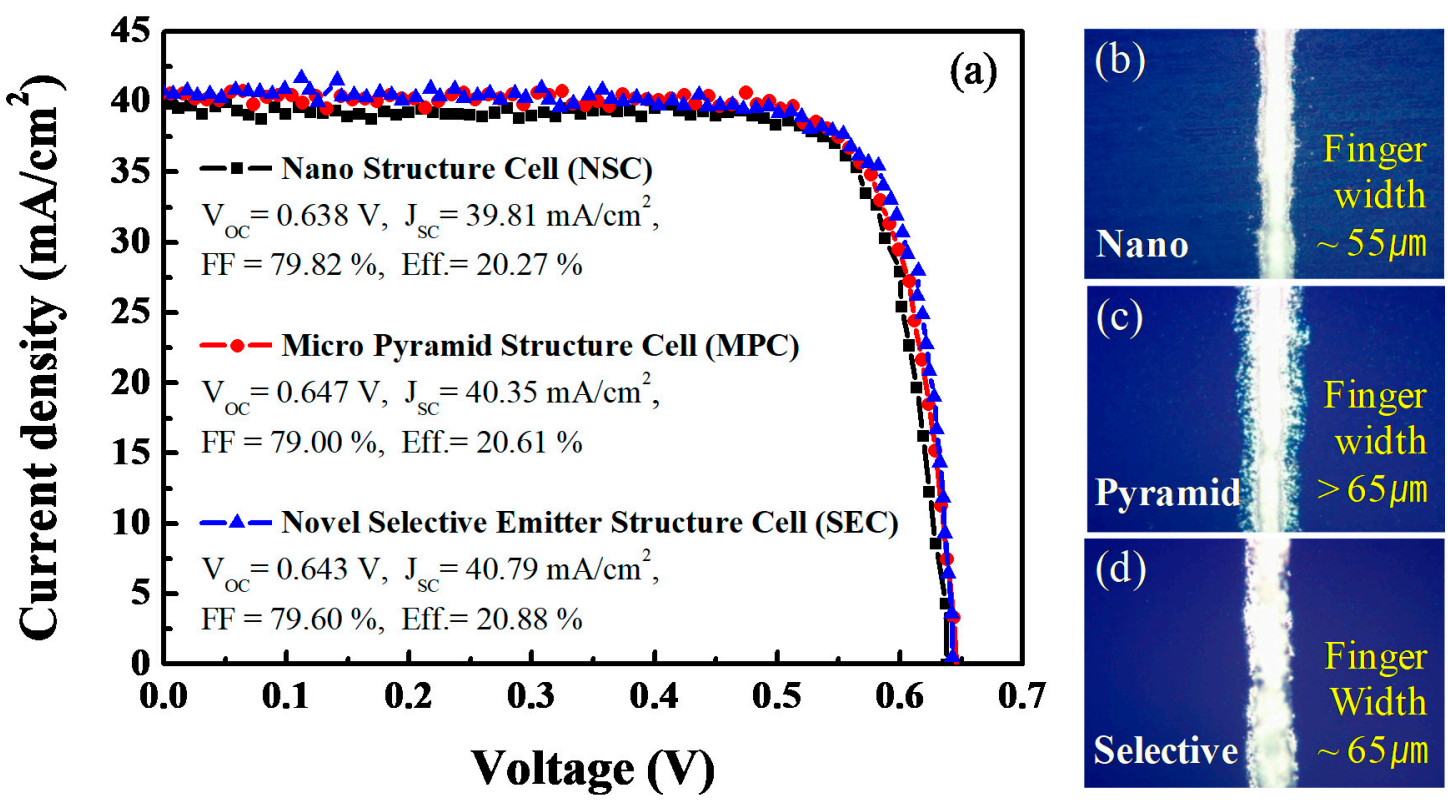

Figure 8. Light density-voltage (J-V) characteristic analysis of crystalline silicon (c-Si) solar cells according to surface morphology and printed front Ag electrode shape, (a) result of light J-V, (b) optical microscope (OM) image of printed front Ag electrode shape on nanostructured solar cell surface, (c) OM image of printed front Ag electrode shape on micro-pyramid-structured solar cell surface, (d) OM image of printed front Ag electrode shape on the novel SE-structured solar cell surface.

The J-V curve results for the novel SE structure cell (SEC) using nanostructure and micro-pyramid structure had a current density $\left(\mathrm{J}_{\mathrm{SC}}\right)$ of $40.79 \mathrm{~mA} / \mathrm{cm}^{2}$, open-circuit voltage $\left(\mathrm{V}_{\mathrm{OC}}\right)$ of $643 \mathrm{mV}$, fill factor (FF) of $79.60 \%$, and conversion efficiency of $20.88 \%$. The improvement in the SEC efficiency of the selective surface structure emitter was analyzed by an FF increase $(0.6 \%)$ and a JSC increase $(0.44$ $\mathrm{mA} / \mathrm{cm}^{2}$ ) with respect to those of the MPC. The improvement in the fill factor (FF) was also observed in the internal quantum efficiency (IQE) results of Figure 9 due to the low contact resistance of the nanostructure electrode contacts.

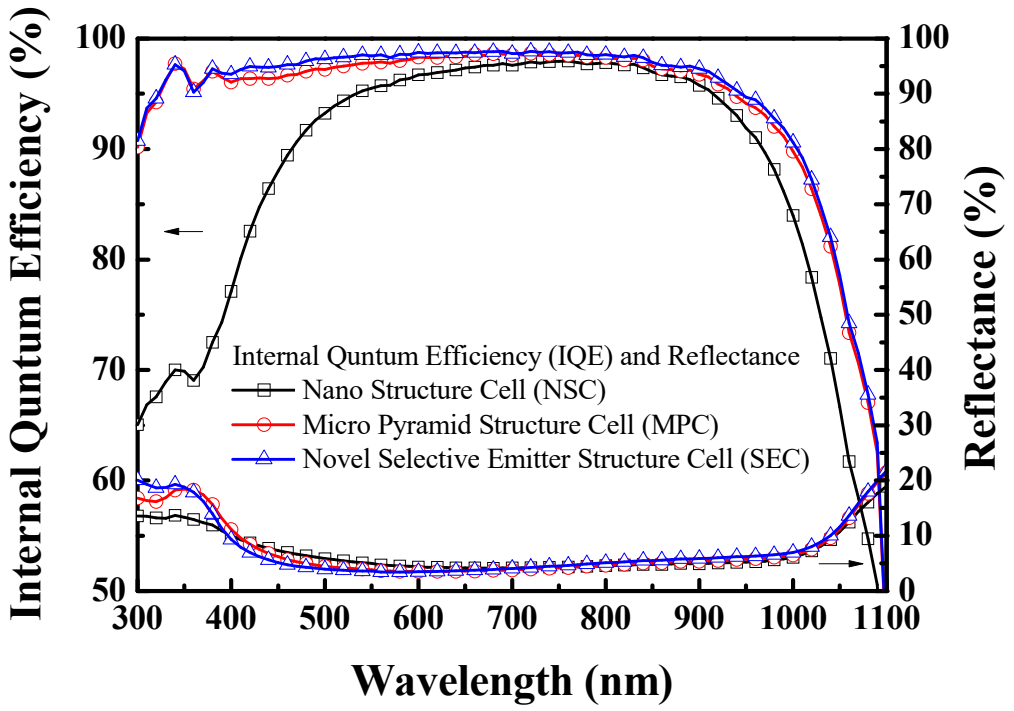

Figure 9. Result of reflectance and internal quantum efficiency (IQE) of c-Si solar cells according to surface morphology.

In the 300 to $400 \mathrm{~nm}$ region observed as the recombination characteristics of the surface emitter, similar analytical results as the micro-pyramid structure were shown, but improved IQE of average 
$0.56 \%$ and maximum $1.1 \%$ in the wavelength range of 400 to $1100 \mathrm{~nm}$ were obtained. The improvement in the IQE shows the characteristic of decreasing the series resistance, which also affects the improvement in the fill factor (FF) [34]. The improvement in the short circuit current density (JSC) is confirmed by the improvement in the shading loss of the screen-printing electrode according to the surface structure of Figure $8 \mathrm{~b}-\mathrm{d}$. The screen-printed electrode lines on the nanostructure surface showed a clean edge electrode shape of about $55 \mu \mathrm{m}$ shown in Figure 8b. In the micro-pyramid structure of Figure $8 \mathrm{c}$, the screen-printed electrode line width was approximately $65 \mu \mathrm{m}$ or more by electrode spreading. It can be seen from the literature that the short-circuit current density was lowered due to the shading loss by the electrode spreading caused by the action of the Ag particle size of the screen-printing electrode and the micro-pyramid structure size [35]. As shown in Figure 8d, the printed electrode line width of the selective surface structure was approximately $65 \mu \mathrm{m}$ and a clean edge electrode shape was observed. The shape of the clean edge electrode by the selective surface structure minimized the shading loss and could obtain improved characteristics of short circuit current density $\left(\mathrm{J}_{S C}\right)$ compared to a micro-pyramid structure.

In this study, we fabricated a new SE solar cell using the final nanostructure and micro-pyramid structure. This was performed by controlling the difference in sheet resistance in the doping process together with the pyramid structure formed in the texturing process using the nanostructure formed before the texturing process. As the size of the nanostructure became smaller, the emitter sheet resistance of the doped sample became smaller. The difference in sheet resistance between the nanostructure and the pyramid structure was found to be the largest in the range of the emitter doping condition of 100 to $150 \Omega / \mathrm{sq}$ at the micro-pyramid structure. These experimental facts have been confirmed by the SIMS analysis and the literature, which show that the nanostructure had more frequent valleys and peaks than that of the micro-pyramid structure. As a result of the characteristics of the solar cell having the novel SE using the nanostructure, the efficiency of $20.88 \%$ was improved by about $0.27 \%$ compared to the conventional pyramid structure with the efficiency of $20.61 \%$. This improvement was obtained by improving the fill factor (FF) through the contact of the electrode with the low sheet resistance surface on the nanostructure. It also obtained an improvement in the short circuit current density (JSC) by minimizing the shadow loss of the electrode printed on the nanostructure surface.

\section{Conclusions}

In this study, a novel SE technique that uses selective nanosurface morphologies for a heavy emitter area was proposed before the pyramid texturing process [3-24]. The SE technology, which used different surface morphologies, exhibited different sheet resistances despite the nano/micro-structure regions being doped with a single doping process. It was also possible to control the difference in sheet resistance during the doping process by changing the temperature, pre-deposition time, and drive-in time. The result of the uniformly doped sheet resistance on the standard micro-pyramidal surface was about $82 \Omega / \mathrm{sq}$, and the doping results of the selectively formed nano/micro-surface were 62 and 82 $\Omega /$ sq, respectively. As a result, doped-on selectively formed nano/micro-surfaces SE cells showed a JSC increase $\left(0.44 \mathrm{~mA} / \mathrm{cm}^{2}\right)$ and an FF increase $(0.6 \%)$ compared to the homogeneously doped cells on the micro-pyramid surface, which resulted in about $0.27 \%$ enhanced conversion efficiency.

The novel SE technology that uses nano/micro-structures with similar form to the selective epitaxial layer growth SE technology blocked the risk of solar cell manufacturing processes such as contamination, surface damage, reflectance loss, and over-alignment loss. At each different height location, the nanostructure and the micro-pyramid structure were formed on the silicon surface. Therefore, alignment loss could be minimized by easily aligning the front printed electrode to the high-level location region on the nanosurface.

Author Contributions: Conceptualization, M.J.; methodology, M.J.; validation, Y.H.C., Y.K., and E.-C.C.; formal analysis, M.J., J.P., and Y.H.C.; investigation, M.J.; data curation, M.J., J.P., and Y.H.C.; writing-original draft preparation, M.J. and Y.K.; writing—review and editing, M.J., Y.K., and E.-C.C.; supervision, D.L., E.-C.C., and J.Y.; 
project administration, E.-C.C.; funding acquisition, D.L, E.-C.C., and J.Y. All authors have read and agreed to the published version of the manuscript.

Funding: This work was supported by the Korea Institute of Energy Technology Evaluation and Planning (KETEP) and the Ministry of Trade, Industry and Energy (MOTIE) of the Republic of Korea (No. 20203030010310 and No. 20173010013740).

Conflicts of Interest: The authors declare no conflict of interest.

\section{References}

1. Green, M.A. The path to $25 \%$ silicon solar cell efficiency: History of silicon cell evolution. Prog. Photovolt. Res. Appl. 2009, 17, 183-189. [CrossRef]

2. Swanson, R.M. A vision for crystalline silicon photovoltaics. Prog. Photovolt. Res. Appl. 2006, 14, $443-453$. [CrossRef]

3. ITRPV 2020. International Technology Roadmap for Photovoltaic (ITRPV) Eleventh Edition-2019 Results; ITRPV: Frankfurt, Germany, 2020.

4. Gassenbauer, Y.; Ramspeck, K.; Bethmann, B.; Dressler, K.; Moschner, J.D.; Fiedler, M.; Brouwer, E.; Drößler, R.; Lenck, N.; Heyer, F.; et al. Rear-Surface Passivation Technology for Crystalline Silicon Solar Sells: A Versatile Process for Mass Production. IEEE J. Photovolt. 2013, 3, 125-130. [CrossRef]

5. Green, M.A. The passivated emitter and rear cell (PERC): From conception to mass production. Sol. Energy Mater. Sol. Cells 2015, 143, 190-197. [CrossRef]

6. Chunduri, S.K.; Schmela, M. High Efficiency Cell Technologies 2019 From PERC to Passicated Contacts and HJT. Taiyang News, 2019.

7. Min, B.; Wagner, H.; Müller, M.; Neuhaus, H.; Brendel, R.; Altermatt, P.P. Incremental efficiency improvements of mass-produced PERC cells up to $24 \%$, predicted solely with continuous development of existing technologies and wafer materials. In Proceedings of the 31st European Photovoltaic Solar Energy Conference and Exhibition, Hamburg, Germany, 14-18 September 2015; pp. 473-476.

8. Hahn, G. Status of selective emitter technology. In Proceedings of the 25th European Photovoltaic Solar Energy Conference and Exhibition and 5th World Conference on photovoltaic Energy Conversion, Munich, Germany, 6-10 September 2010; pp. 1091-1096.

9. Rahman, M.Z. Status of selective emitters for p-type c-Si solar cells. Opt. Photonics J. 2012, 2, $129-134$. [CrossRef]

10. Lv, Y.; Zhuang, Y.F.; Wang, W.J.; Wei, W.W.; Sheng, J.; Zhang, S.; Shen, W.Z. Towards high-efficiency industrial p-type mono-like Si PERC solar cells. Sol. Energy Mater. Sol. Cells 2020, 204, 110202. [CrossRef]

11. Tonini, D.; Borrosso, C.; Cellere, G.; Furin, V.; Galiazzo, M.; Kumar, P.; Tanner, D.; Voltan, A. Efficiency gain in c-Si cells through selective emitter and double printing. Energy Procedia 2011, 8, 598-606. [CrossRef]

12. Horzel, J.; Szlufcik, J.; Nijs, J.; Mertens, R. A simple processing sequence for selective emitters [Si solar cells]. In Proceedings of the Conference Record of the Twenty Sixth IEEE Photovoltaic Specialists Conference, Anaheim, CA, USA, 29 September-3 October 1997; pp. 139-142.

13. Antoniadis, H. Silicon ink high efficiency solar cells. In Proceedings of the 34th IEEE Photovoltaic Specialists Conference, Philadelphia, PA, USA, 7-12 June 2009; pp. 000650-000654.

14. Zhong, S.; Shen, W.; Liu, F.; Li, X. Mass production of high efficiency selective emitter crystalline silicon solar cells employing phosphorus ink technology. Sol. Energy Mater. Sol. Cells 2013, 117, 483-488. [CrossRef]

15. Lauermann, T.; Book, F.; Dastgheib-Shirazi, A.; Hahn, G.; Haverkamp, H.; Bleidiessel, R.; Fleuster, M. The optimal choice of the doping levels in an inline selective emitter design for screen printed multicrystalline silicon solar cells. In Proceedings of the 24th European Photovoltaic Solar Energy Conference and Exhibition, Hamburg, Germany, 21-24 September 2009; pp. 1795-1797.

16. Basu, P.K.; Cunnusamy, J.; Sarangi, D.; Boreland, M.B. Novel selective emitter process using non-acidic etch-back for inline-diffused silicon wafer solar cells. Renew. Energy 2014, 66, 69-77. [CrossRef]

17. Book, F.; Raabe, B.; Hahn, G. Two diffusion step selective emitter: Comparison of mask opening by laser or etching paste. In Proceedings of the 23rd European Photovoltaic Solar Energy Conference and Exhibition, Valencia, Spain, 1-5 September 2008; pp. 1546-1549. 
18. Engelhardt, J.; Kromer, H.; Hahn, G.; Terheiden, B. Laser doping from as-deposited CVD layers for high-efficiency crystalline silicon solar cells. In Proceedings of the Silicon PV 2019, the 9th International Conference on Crystalline Silicon Photovoltaics, Leuven, Belgium, 8-10 April 2019; Volume 2147, p. 070002.

19. Kim, M.; Kim, D.; Kim, D.; Kang, Y. Influence of laser damage on the performance of selective emitter solar cell fabricated using laser doping process. Sol. Energy Mater. Sol. Cells 2015, 132, 215-220. [CrossRef]

20. Raabe, B.; Haverkamp, H.; Book, F.; Dastgheib-Shirazi, A.; Moll, R.; Hahn, G. Monocrystalline silicon: Future cell concepts. In Proceedings of the 22nd European Photovoltaic Solar Energy Conference and Exhibition, Milano, Italy, 3-7 September 2007; pp. 1024-1029.

21. Pal, B.; Ray, S.; Gangopadhyay, U.; Ray, P.P. Novel technique for fabrication of n-type crystalline silicon selective emitter for solar cell processing. Mater. Res. Express 2019, 6, 075523. [CrossRef]

22. Low, R.; Gupta, A.; Bateman, N.; Ramappa, D.; Sullivan, P.; Skinner, W.; Mullin, J.; Peters, S.; Weiss-Wallrath, H. High efficiency selective emitter enabled through patterned ion implantation. In Proceedings of the 35th IEEE Photovoltaic Specialists Conference, Honolulu, HI, USA, 20-25 June 2010; pp. 001440-001445.

23. Dubé, C.E.; Tsefrekas, B.; Buzby, D.; Tavares, R.; Zhang, W.; Gupta, A.; Low, R.J.; Skinner, W.; Mullin, J. High efficiency selective emitter cells using patterned ion implantation. Energy Procedia 2011, 8, 706-711. [CrossRef]

24. Payo, M.R.; Li, Y.; Russell, R.; Singh, S.; Filipek, I.K.; Duerinckx, F.; Szlufcik, J.; Poortmans, J. Efficiency gain in plated bifacial n-type PERT cells by means of a selective emitter approach using selective epitaxy. Sol. Energy Mater. Sol. Cells 2020, 204, 110173. [CrossRef]

25. Ju, M.; Balaji, N.; Lee, Y.; Park, C.; Song, K.; Choi, J.; Yi, J. Novel vapor texturing method for EFG silicon solar cell applications. Sol. Energy Mater. Sol. Cells 2012, 107, 366-372. [CrossRef]

26. Ju, M.; Balaji, N.; Park, C.; Nguyen, H.T.T.; Cui, J.; Oh, D.; Jeon, M.; Kang, J.; Shim, G.; Yi, J. The effect of small pyramid texturing on the enhanced passivation and efficiency of single c-Si solar cells. RSC Adv. 2016, 6, 49831-49838. [CrossRef]

27. Komatsu, Y.; Harata, D.; Schuring, E.W.; Vlooswijk, A.H.G.; Katori, S.; Fujita, S.; Venema, P.R.; Cesar, I. Calibration of electrochemical capacitance-voltage method on pyramid texture surface using scanning electron microscopy. Energy Procedia 2013, 38, 94-100. [CrossRef]

28. Li, H.; Ma, F.; Hameiri, Z.; Wenham, S.; Abbott, M. On elimination of inactive phosphorus in industrial $\mathrm{POCl}_{3}$ diffused emitters for high efficiency silicon solar cells. Sol. Energy Mater. Sol. Cells 2017, 171, $213-221$. [CrossRef]

29. Kafle, B.; Schön, J.; Fleischmann, C.; Werner, S.; Wolf, A.; Clochard, L.; Duffy, E.; Hofmann, M.; Rentsch, J. On the emitter formation in nanotextured silicon solar cells to achieve improved electrical performances. Sol. Energy Mater. Sol. Cells 2016, 152, 94-102. [CrossRef]

30. Es, F.; Baytemir, G.; Kulakci, M.; Turan, R. Metal-assisted nano-textured solar cells with $\mathrm{SiO}_{2} / \mathrm{Si}_{3} \mathrm{~N}_{4}$ passivation. Sol. Energy Mater. Sol. Cells 2017, 160, 269-274. [CrossRef]

31. Voyer, C.; Buettner, T.; Bock, R.; Biro, D.; Preu, R. Microscopic homogeneity of emitters formed on textured silicon using in-line diffusion and phosphoric acid as the dopant source. Sol. Energy Mater. Sol. Cells 2009, 93, 932-935. [CrossRef]

32. Dastgheib-Shirazi, A.; Steyer, M.; Micard, G.; Wagner, H.; Altermatt, P.P.; Hahn, G. Relationships between diffusion parameters and phosphorus precipitation during the $\mathrm{POCl}_{3}$ diffusion process. Energy Procedia 2013, 38, 254-262. [CrossRef]

33. Shanmugam, V.; Cunnusamy, J.; Khanna, A.; Basu, P.K.; Zhang, Y.; Chen, C.; Stassen, A.F.; Boreland, M.B.; Mueller, T.; Hoex, B.; et al. Electrical and microstructural analysis of contact formation on lightly doped phosphorus emitters using thick-film Ag screen printing pastes. IEEE J. Photovolt. 2013, 4, 168-174. [CrossRef]

34. Yang, Y.; Seyedmohammadi, S.; Kumar, U.; Gnizak, D.; Graddy, E.; Shaikh, A. Screen printable silver paste for silicon solar cells with high sheet resistance emitters. Energy Procedia 2011, 8, 607-613. [CrossRef]

35. Ju, M.; Mallem, K.; Dutta, S.; Balaji, N.; Oh, D.; Cho, E.; Cho, Y.H.; Kim, Y.; Yi, J. Influence of small size pyramid texturing on contact shading loss and performance analysis of Ag-screen printed mono crystalline silicon solar cells. Mater. Sci. Semicond. Process. 2018, 85, 68-75. [CrossRef]

(C) 2020 by the authors. Licensee MDPI, Basel, Switzerland. This article is an open access article distributed under the terms and conditions of the Creative Commons Attribution (CC BY) license (http://creativecommons.org/licenses/by/4.0/). 